\title{
Safety Risk Prediction and Early Warning Model and System Design of Chemical Enterprises Based on GIS and Internet of Things
}

\author{
Di Li , Jianzhong Sun \\ Safite Engineering Technology Group Co., Ltd, \\ Qingdao, China \\ 1003343600@qq.com

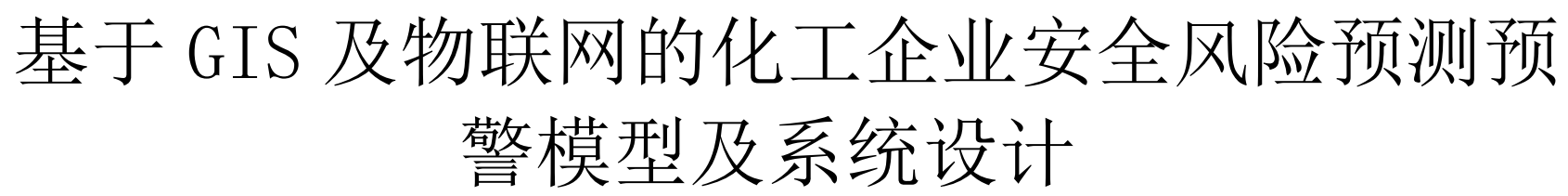

李迪, 孙建中

赛飞特工程技术集团有限公司

青岛 266100，中国

1003343600@qq.com

\begin{abstract}
In order to predict the safety risks of chemical enterprises in real time, a GIS-based risk prediction and warning system for chemical enterprises was developed. The system uses GIS geographic information platform combined with Internet of Things data acquisition equipment to collect and process dangerous source data; use risk early warning model to conduct data mining and analysis of collected information, and obtain GIS-based risk prediction and early warning results; The security risk distribution is comprehensively warned to form a map of security risks, providing auxiliary decision support for safety production management.
\end{abstract}

Keywords—chemical safety; early risk warning indicators; risk prediction and early warning; GIS geographic information system; map of security risks;

摘要一为实时对化工企业安全风险进行预测预警, 研究了 相关预警模型, 并开发了基于 GIS 的化工企业风险预测预警 系统。该系统利用 GIS 地理信息平台结合物联网数据采集设 备对危险源数据进行采集处理; 利用风险预警模型对采集的 信息进行数据挖掘分析，得出基于 GIS 的风险预测预警结 果; 利用 GIS 展现平台对企业安全风险分布进行综合预警, 形成安全风险一张图, 为安全生产管理提供辅助决策支持。

关键词一化工安全, 风险预测预警, GIS 地理信息系统, 安全风险一张图

\section{I. 引言}

大化工生产工艺流程和控制技术日益复杂化，化学 反应种类多且能源消耗大, 生产过程的废弃物成分复杂 多样, 企业安全风险错综复杂。利用风险识别、分析与 预警理论, 分析化工企业生产过程的致灾因子与事故隐 患, 利用现有自动化控制系统监测与报警技术, 建立风 险预测预警模型, 实现事故预防关口前移, 风险实时管 控。
同时，在风险预测预警结果中结合地理信息系统 GIS，利用 GIS 地理空间数据和地理模型分析方法，可 为化工安全风险预测实时提供多种空间的和动态的地理 信息，为化工企业安全生产提供辅助决策支持。为此， 我们开发了基于 GIS 的化工企业（园区）风险预测预警 系统，可实现化工企业（园区）安全风险的 GIS 动态展 现和安全风险一张图，管理人员能及时发现问题和知晓 风险分布, 辅助进行安全管理及决策。

\section{II.＼cjkstart典型化工生产安全风险预警指标体系构建}

化工生产过程中存在诸多危险因素和事故隐患, 风 险预警体现了一种从现象到本质、从预警指标度量值到 预警值的非线性关系，建立科学性、系统性且层次分明 的风险预警指标体系是风险预警的关键环节。指标构建 的基本程序如图 1 所示。

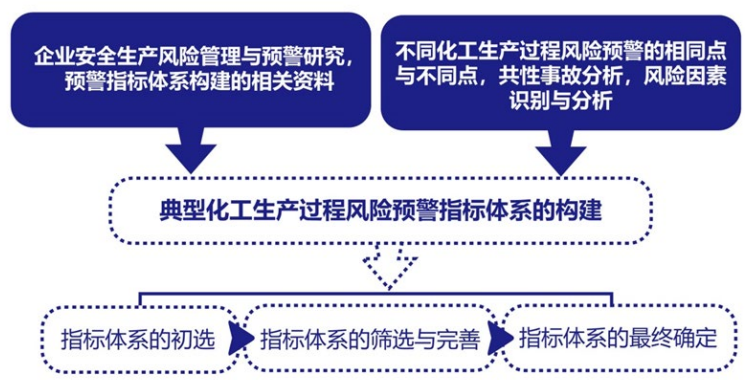

图 1 风险预警指标体系构建程序

风险预警指标需要对风险因素、风险事件、风险损 失及风险自身等全面的识别，明确风险识别的边界条件 是关键之一。风险预警指标选取可能性影响因素、严重 性影响因素和敏感性影响因素作为风险评价指标，建立 三维风险模型用于重大危险源的风险分级研究, 并以 
$R=f(P, L, S, D)$ 表示风险值（其中，P 表示可能性， L 表 示严重性, $\mathrm{S}$ 表示敏感性, D 表示风险位置)。我们在 现有关于典型化工生产风险研究的基础上, 选取可能 性、严重性以及敏感性作为典型化工生产过程风险因素 识别的边界条件, 为构建风险预警指标体系提供依据, 同时在每个风险点上标识位置信息, 下图为化工企业安 全风险典型指标。

\section{典型化工生产过程风险因素}

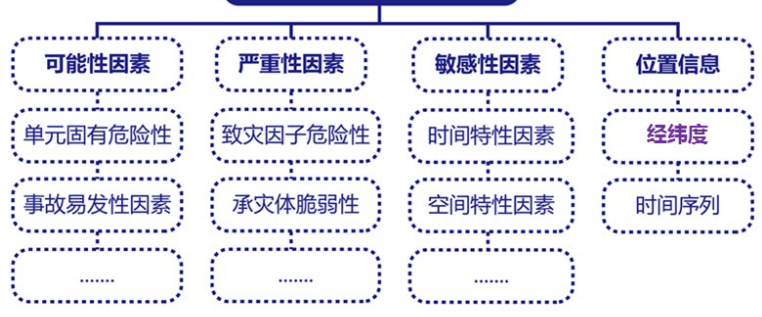

图 2 安全风险预警一级指标体系

无化工企业安全风险预警指标体系, 要求能够体现 生产过程风险的状态及事故隐患的演变状况。以风险因 素识别与分析为基础, 选取可能性因素、严重性因素及 敏感性因素作为一级指标体系。指标选定时, 为了实现 对化工生产过程事故隐患的覆盖性, 充分考虑指标的兄 余性特征, 构建包括 13 个二级预警指标, 63 个三级预 警指标，限于篇幅原因，就不一一赘述。

\section{III. 化工生产风险预警模型}

化工生产过程风险预警是衡量生产状态偏离既定预 警界限的强弱程度或趋势, 根据实时情况发出预警信 号, 并及时采取有效防范措施的管理系统。化工生产过 程风险预警主要依据预警指标体系与既定的预警值, 借 助风险预警模型, 实现对化工生产过程风险状态变化趋 势的预警与预测。

\section{1 预警指标确定}

对于预警界限具体数值的确定, 尚未形成系统的方 法, 应根据研究对象的实际情况而定。本文根据预警指 标风险状态值的划分, 确定系统整体风险预警界限, 但 只有部分指标能够参考相应的国家和行业标准, 其余指 标需结合生产实际、综合现有相关文献研究, 通过咨询 行业专家确定。下表为部分风险预警指标的预警界限。

\begin{tabular}{cccccc}
\hline 风险预警指标 & 安全 & 较安全 & 危险 & 很危险 & 极危险 \\
\hline 物料及产品固有危险性 $\mathrm{P}_{11}$ & $\mathrm{~F}<1$ & $1 \leq \mathrm{F}<2$ & $2 \leq \mathrm{F}<3$ & $3 \leq \mathrm{F}<4$ & $\mathrm{~F} \geq 4$ \\
工艺固有危险性 $\mathrm{P}_{12}$ & $\mathrm{~F}<2$ & $2 \leq \mathrm{F}<5$ & $5 \leq \mathrm{F}<16$ & $16 \leq \mathrm{F}<21$ & $\mathrm{~F} \geq 21$ \\
装置设备固有危险性 $\mathrm{P}_{13}$ & $\mathrm{~F}<3$ & $3 \leq \mathrm{F}<5$ & $5 \leq \mathrm{F}<7$ & $7 \leq \mathrm{F}<9$ & $\mathrm{~F} \geq 9$ \\
物质.工艺危险相关性 $\mathrm{P}_{14}$ & $\mathrm{~F}<0.2$ & $0.2 \leq \mathrm{F}<0.5$ & $0.5 \leq \mathrm{F}<0.7$ & $0.7 \leq \mathrm{F}<0.9$ & $\mathrm{~F} \geq 0.9$ \\
物质危险感度 $\mathrm{P}_{21}$ & $\mathrm{~F}<0.3$ & $0.3 \leq \mathrm{F}<0.5$ & $0.5 \leq \mathrm{F}<0.7$ & $0.7 \leq \mathrm{F}<0.9$ & $\mathrm{~F} \geq 0.9$ \\
储存运输系统完好率 $\mathrm{P}_{22}$ & $\mathrm{~F} \geq 90$ & $80 \leq \mathrm{F}<90$ & $70 \leq \mathrm{F}<80$ & $60 \leq \mathrm{F}<70$ & $\mathrm{~F}<60$ \\
化学反应危险性 $\mathrm{P}_{23}$ & $\mathrm{~F}<1$ & $1 \leq \mathrm{F}<2$ & $2 \leq \mathrm{F}<3$ & $3 \leq \mathrm{F}<4$ & $\mathrm{~F} \geq 4$ \\
\hline
\end{tabular}

3.2 风险预警数据输入

风险预警信息采集与获取是实现风险预警管理的基 础, 全面准确的风险信息采集以自动化控制系统监测为 主、人员检测为辅。

风险预警的输入应以能够全面体现参与生产活动各 单元, 或设备运行状态的风险因素为基础。以预警指标
系统的层次和维度划分为基准，对获取的风险预警信息 进行整理与归纳。从风险事故发生的可能性、事故后果 的严重性以及系统对风险因素的敏感性三个维度, 衡量 风险因素对化工生产安全稳态的影响, 并将三维预警信 息的数据值作为风险预警模型的输入。

\section{3 安全风险预警模型拟合}

影响化工安全生产的因素复杂多样, 为了能够达到 风险预警的最终目标, 实现从局部到整体, 从预警指标 到系统综合的风险预警过程。典型化工生产过程风险预 警应分层逐级进行, 构建 “串联式” 分级风险预警模 型, 如图 3 所示。子系统风险预警从不同的维度独立开 展分析, 有助于识别风险因素并获取事故隐患和诱因。 系统综合预警以子系统风险因素的耦合，指明系统风险 状态的关键致灾因素, 并根据风险预警输出值, 提出相 应有效的管控措施。

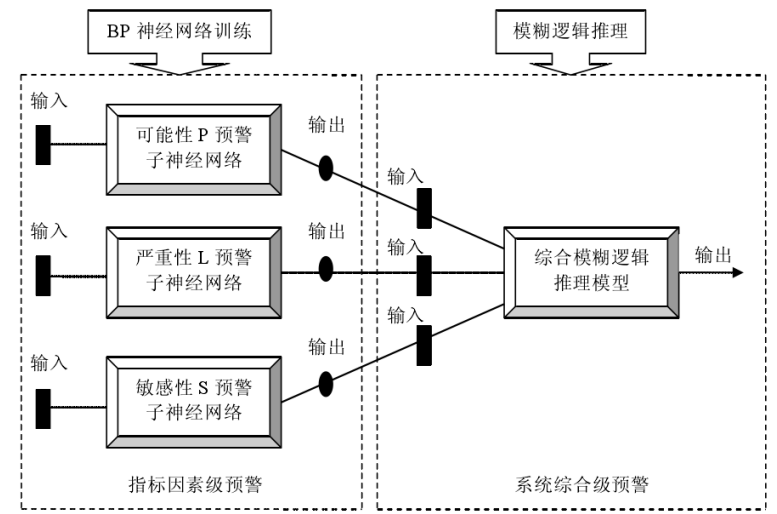

图 3 安全风险预警模型

\section{4 安全风险预警值}

系统综合预警值是化工企业安全生产整体风险状态 的体现，将整体预警值进行归一化处理。以现有风险预 警理论与技术研究为基础, 根据化工企业现有毒气检测 和火灾报警等自动化监控与报警系统的具体方案与实际 运行状况, 咨询行业专家确定典型化工生产过程系统综 合预警界限，见下表所示。

表 3-1 安全风险预警值

\begin{tabular}{|c|c|c|c|c|}
\hline $\begin{array}{c}\text { 预警指 } \\
\text { 数 }\end{array}$ & $\mathrm{F}<65$ & $\begin{array}{c}65 \leq \mathrm{F}< \\
75\end{array}$ & $\begin{array}{c}75 \leq \mathrm{F}< \\
85\end{array}$ & $85 \leq \mathrm{F}$ \\
\hline $\begin{array}{c}\text { 风险等 } \\
\text { 级 }\end{array}$ & 低 & 一般 & 较高 & 高 \\
\hline $\begin{array}{c}\text { 预警等 } \\
\text { 级 }\end{array}$ & 四级 & 三级 & 二级 & 一级 \\
\hline $\begin{array}{c}\text { 预警信 } \\
\text { 号 }\end{array}$ & 蓝色 & 黄色 & 橙色 & 红色 \\
\hline
\end{tabular}




\section{IV. 安全风险一张图平台（预警结果输出）}

安全风险一张图平台是以 GIS 地理信息系统为基 础, 以企业 GIS 地图服务和 GIS 图形渲染为手段, 建立 与现实一致的三维企业场景, 将企业周边地形、地貌等 地理信息以及安全风险分布数据等融合至三维空间模 型，使得企业真实场景与数字地球有效融为一体，三维 地图与风险融为一体，形成企业安全风险信息管理的载 体。

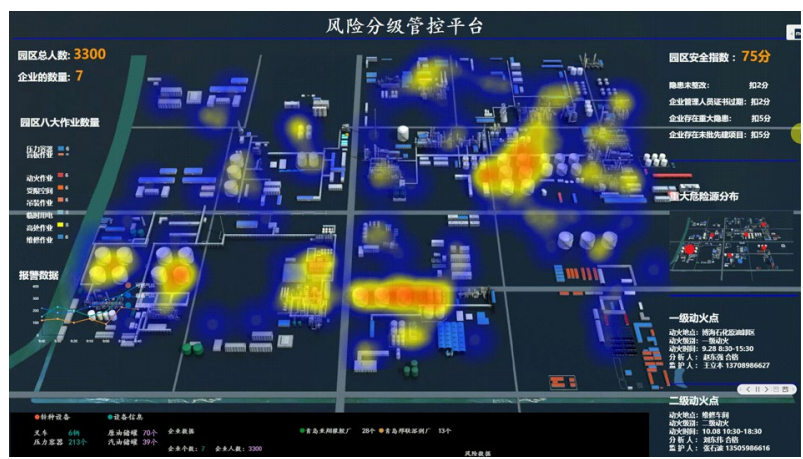

图 4 化工园区（企业）安全风险一张图平台

预警信息三维可视化展现模块可对化工企业安全风 险预警结论进行 GIS 地图的三维可视化展现, 可对风险 信息的级别、类别、状态细节、风险处置情况等相关信 息通过多种专题图表的形式进行展现, 例如区域风险热 力图、风险专项指标统计图、风险指标等级图等。

模块也支持按图形模式、路径选择模式、智能搜索 模式进行风险信息的交互式查询定位，查询结果在 GIS 地图上高亮显示, 并以列表方式详细显示该企业装置风 险分布情况和风险信息统计情况, 能够使企业安全管理 人员直观了解区域安全风险预警评估情况。同时, 系统 在遇到预警或报警信息时, 可实现风险信息的自动一键 定位。

\section{V. 意义}

（1）解决风险底数不清、情况不明问题

通过建立安全风险一张图平台, 将厂区安全风险以 分级辨识评估, 并整合 GIS 地理位置信息, 实现安全风 险的数据化、位置化，从而解决底数不清、情况不明问 题。

（2）建立动态风险管控机制

安全风险数据实时采集、实时评估, 风险的等级及 结果都是基于实时的数据分析模型实时计算得出, 这样 建立起对安全风险的实时评估系统, 管理人员借助安全 风险分级管控系统，做到高风险区域重点管控，有的放 矢, 从而建立起对风险的实时动态管控机制。

\section{VI. 结论}

通过建立化工企业安全风险预警指标、构建预警模 型，并开发基于 GIS 的化工企业风险预测预警系统，实 现了化工企业安全风险的 “一张图” 综合可视化展现, 便于风险预测预警信息的可视化管理，并通过构建企业 风险预警模型对化工风险进行分级评价，实现了风险治 理全方位、全过程管控, 为企业的安全生产提供了决策 支持和技术保障。

参考文献

[1] 于勇. 油气初加工风险预警技术分析 [J]. 化工管理. 2019 (17)

[2] 李文, 武玉梁. 煤矿危险源风险预警与控制的研究 [J]. 中国安全 生产科学技术.

[3] 罗云,宫运华,宫宝霖,解增武,孙晓祎.安全风险预警技术研究[J]. 安 全. 2005(02).

[4] 黄家敏,张继光,常德政治金企业安全风险预警模式及应用[J].. 河 南冶金. 2018(02)

[5] 徐文.基于信息化的风险预警平台构建与应用 [J]. 天然气与石油. 2017(05).

[6] 陈思羽.浅谈小型化工企业火灾事故特点及预防 [J]. 江西化工. 2012(02).

[7] 周蓉.企业安全事故风险预警技术研究[J]. 中国商界(下半月). 2008(06)。

[8] 谢俊成; 夏立伟. 多源数据融合下的石化企业火灾事故风险预警与 安全应急. 中国石油和化工标准与质量. 2019 (02). 